\title{
BMJ Open Risk factors for maternal morbidity in Victoria, Australia: a population-based study
}

\author{
Anthea C Lindquist, ${ }^{1,2}$ Jennifer J Kurinczuk, ${ }^{1}$ Euan M Wallace, ${ }^{2,3}$ Jeremy Oats, ${ }^{4}$ \\ Marian Knight ${ }^{1}$
}

To cite: Lindquist AC, Kurinczuk JJ, Wallace EM, et al. Risk factors for maternal morbidity in Victoria, Australia: a population-based study. BMJ Open 2015;5:e007903. doi:10.1136/bmjopen-2015007903

- Prepublication history for this paper is available online. To view these files please visit the journal online (http://dx.doi.org/10.1136/ bmjopen-2015-007903).

Received 9 February 2015 Revised 21 July 2015 Accepted 27 July 2015

CrossMark

For numbered affiliations see end of article.

Correspondence to Dr Anthea C Lindquist; aclin123@gmail.com

\section{ABSTRACT}

Objectives: The aim of this analysis was to quantify the risk factors associated with maternal morbidity among women in Victoria, Australia, focusing particularly on sociodemographic factors.

Design: Case-control analysis.

Participants: Data on all maternities in Victoria from 1 January 2006 to 31 December 2008.

Methods: A case-control analysis was conducted using unconditional logistic regression to calculate adjusted ORs (aORs). Cases were defined as all women noted to have had a severe complication during the index pregnancy. Severe maternal morbidity was defined by the validated, composite Australian Maternal Morbidity Outcome Indicator. Socioeconomic position was defined by Socio-Economic Indices for Areas (SEIFA), specifically the Index of Relative Socioeconomic Disadvantage (IRSD), and other variables analysed were age, parity, Indigenous background, multiple pregnancy, country of birth, coexisting medical condition, previous caesarean section, spontaneous abortion or ectopic pregnancy.

Results: The study population comprised 211060 women, including 1119 cases of severe maternal morbidity $(0.53 \%)$. Compared with the highest IRSD quintile, the aOR for the 2nd quintile was $1.23(95 \% \mathrm{Cl}$ 1.03 to 1.49$), 0.98$ ( $(95 \% \mathrm{Cl} 0.79$ to 1.21$)$ for the $3 \mathrm{rd}$ quintile, $1.55(95 \% \mathrm{Cl} 1.28$ to 1.87$)$ for the 4 th and $1.21(95 \% \mathrm{Cl} 1.00$ to 1.47 ) for the lowest (most deprived) quintile. Indigenous status was associated with twice (aOR 2.02; 95\% $\mathrm{Cl} 1.32$ to 3.09 ) the odds of being a case. Other risk factors for severe maternal morbidity were age $\geq 35$ years (aOR $1.22 ; 95 \% \mathrm{Cl} 1.04$ to 1.44 ), coexisting medical condition (aOR $1.39 ; 95 \%$ $\mathrm{Cl} 1.16$ to 1.65 ), multiple pregnancy (aOR $2.30 ; 95 \% \mathrm{Cl}$ 1.71 to 3.10 ), primiparity (aOR $1.36 ; 95 \% \mathrm{Cl} 1.18$ to 1.57), previous caesarean section (aOR $1.79 ; 95 \% \mathrm{Cl}$ 1.53 to 2.10 ) and previous spontaneous miscarriage (aOR 1.25; 95\% Cl 1.08 to 1.44 ).

Conclusions: The findings from Victoria strongly suggest that social disadvantage needs to be acknowledged and further investigated as an independent risk factor for adverse maternal outcomes in Australia and incorporated into appropriate policy planning and healthcare programmes.

\section{Strengths and limitations of this study}

- The size of the database, which included data on all maternities in Victoria during the study period allowed for a large, statistically well-powered study to be performed.

- The availability of a large amount of data on clinical outcomes and demographics for each study participant enabled a range of risk factors for outcomes of several maternal morbidity to be investigated.

- The absence of body mass index (BMI) and smoking status data in the database was a limitation of the study, particularly given the potential associations between socioeconomic position, maternal morbidity and BMI and smoking.

- Socio-Economic Indices for Areas (SEIFA) codes mapped only to large postcode areas may have limited our capacity to assess the impact of small area-based socioeconomic position on maternal outcomes. Nevertheless, we were able to discern important variations by socioeconomic position.

\section{INTRODUCTION}

Internationally, detailed assessment of maternal deaths through formal review, such as the Confidential Enquiry into Maternal Deaths in the UK and the Triennial Maternal Mortality Reports released by the Australian Institute of Health and Welfare, has provided important information on populations of women at risk of maternal death and have been acknowledged as major contributors to the decline in maternal deaths in high-resource countries over the past 50 years. ${ }^{1}$ However, it has also been recognised over the past few decades that in countries where maternal deaths are infrequent, a focus on maternal morbidity can provide more generalisable information that can be used to improve maternal health outcomes and quality of healthcare provision than mortality alone. ${ }^{2-6}$ 
In Australia, State governments are principally responsible for the provision of public healthcare, and the collection of health outcome data is therefore performed routinely at the State rather than national level. While selected State-based data are provided for a national report, more complete data are available in State maternity databases and can be usefully interrogated to explore the prevalence of morbidity and risk factors across a subset of the population. One such database is the Victorian Perinatal Data Collection (VPDC), administered by the Consultative Council for Obstetric and Paediatric Mortality and Morbidity. A statutory population-based surveillance system mandated to collect and analyse information about the health of mothers and babies was established in the state of Victoria in 1982, becoming the VPDC in 2008 and now covering 73755 births per year. ${ }^{78}$ The data collected by VPDC include information about all morbidities which occur in association with pregnancy and birth, thus allowing for analysis of the impact of various demographic and clinical risk factors on a wide range of morbidities.

In order to ensure that the occurrence of adverse outcomes is reduced, it is imperative that high-risk women are identified and managed accordingly through appropriate antenatal and peripartum care. Recent Australian research has suggested that socially disadvantaged women are at increased risk of severe maternal morbidity during pregnancy and labour with women from the lowest socioeconomic group twice as likely than women from the highest group to experience severe complications of pregnancy. ${ }^{8}$ A study in the UK also reported that women from the lowest deprivation quintile were $21 \%$ more likely to experience adverse pregnancy outcomes. ${ }^{9}$ However, both these studies focused solely on women with a small group of the most severe morbidities.

Using data from the VPDC, the aim of this analysis was to quantify the risk factors associated with maternal morbidity among women in Victoria using a previously described maternal morbidity outcome indicator, ${ }^{10}$ focusing particularly on sociodemographic factors.

\section{METHODS}

\section{Data collection and variables}

We used information recorded in the VPDC from 1 January 2006 to 31 December 2008 and included all maternities in Victoria during that time. VPDC data on maternal demographics, obstetric conditions, procedures and outcomes, neonatal morbidity, and birth defects are collected via a mandatory birth report ${ }^{11}$ completed by the attendant midwife for every birth in Victoria of at least 20 weeks gestation or greater than $400 \mathrm{~g}$ birthweight (if gestation is unknown): $:^{7}$ all births including deliveries of women with high-risk pregnancies are attended by a midwife.

Data are checked for completeness on submission to the VPDC and inconsistencies or incomplete data are queried with the reporting hospital. Internal validation of the quality and reliability of the VPDC perinatal data is performed through regular projects designed to verify the accuracy of the coding.

Cases were defined as all women noted to have had a severe complication during the index pregnancy. The definition of severe maternal morbidity used in this analysis is based, with some modification, on the validated, composite Australian Maternal Morbidity Outcome Indicator (MMOI) developed by Roberts $e t a l^{10}$ in 2008 using a compilation of diagnostic and procedural ICD-10 codes (International Classification of Disease; table 1).

Using the postcode information that was available in the database (postcode), socioeconomic position was defined by the Socio-Economic Indices for Areas (SEIFA) measure. The Index of Relative Socioeconomic Disadvantage (IRSD), one of the four indices of SEIFA, was used, which focuses on relative disadvantage and 'summarises a wide range of information about the economic and social resources of people and households within an area'. ${ }^{12}$ Women who identified as Aboriginal or Torres Strait Islander were classified as Indigenous Australian in the data set.

The analytic variable 'maternal medical condition' included ICD-10 coded conditions known to be risk factors for severe maternal morbidity ${ }^{4}{ }^{13-15}$ such as cardiac disease, pre-existing diabetes, epilepsy, essential hypertension, haematological disorders, past thrombotic event (deep vein thrombosis, stroke, pulmonary embolism) and severe mental illness. Obstetric history was limited to number of caesarean sections, ectopic pregnancies and previous spontaneous miscarriage based on information available in the data set.

\section{Statistical analysis}

The characteristics of women with severe maternal morbidity were described and the association between morbidity and individual characteristics was assessed using $\chi^{2}$ analysis. These associations were further explored using univariable logistic regression to generate ORs and $95 \%$ CIs.

Based on the results of the unadjusted analysis and on pre-existing knowledge of risk factors for severe maternal morbidity, potential confounders were selected a priori for inclusion in the multivariable regression model. These variables included Indigenous status, that is, Aboriginal and Torres Strait Islander status, country of birth, age group, coexisting medical conditions and multiple pregnancy. Additional variables to be explored in the model as potential confounders were past caesarean section, parity, past ectopic pregnancy and previous spontaneous abortions (miscarriage). Missing data were dealt with as separate subcategories within each variable. Multivariable analysis was performed in a case-control analysis using unconditional logistic regression in order to calculate adjusted ORs (aORs) with 95\% CIs.

\section{Ethics statement}

Written informed consent from the study participants was not required as all patient records held by the 
Table 1 ICD-10 diagnostic and procedural codes collected in the VPDC database used to define severe maternal morbidity

Diagnoses
Acute abdomen
Acute renal failure
Acute psychosis
Cardiac arrest, failure or infarction
Cerebral oedema or coma
Disseminated intravascular coagulation
Cerebrovascular accident
Major complications of anaesthesia
Obstetric embolism
Shock
Sickle cell anaemia crisis
Status asthmaticus
Status epilepticus
Uterine rupture
ICD-10 codes

K35, K37, K65.0, K65.9, N73.3, N73.5

O90.4, N17, N19, N99.0

F53.1, F23

O89.1, 074.2, 090.3, I21, 142, 143, I46, 150, J81

G93.6, R40.2

D65

160-164

O74.0, 074.2, O74.3, O89.0-089.2, O29.0-029.2 O88

R57, O75.1, T80.5, T88.6

D57.0

J46

G41

O71.0, O71.1

\begin{tabular}{|c|c|}
\hline Procedures & Australian Classification of Health Interventions ICD-10 Procedure codes \\
\hline $\begin{array}{l}\text { Assisted ventilation, including } \\
\text { tracheostomy* }\end{array}$ & $\begin{array}{l}13857-00,13879-00,13882-00,13882-01,13882-02,92038-00,92039-00,92040-00 \\
92041-00,41880-00,41883-00,41883-01,90179-06,92046-00,92047-00\end{array}$ \\
\hline $\begin{array}{l}\text { Curettage in combination with } \\
\text { general anaesthetic }\end{array}$ & $16564-00-01,35640-00-03,92514-10-99,92502-00-03$ \\
\hline Dialysis* & $13100,13112-00,90351-00,13109-00,13109-01,13110-00$ \\
\hline Evacuation of haematoma & $90484-00,90484-01,90484-02,30394-00$ \\
\hline Hysterectomy & $35653-00$ to 03 \\
\hline $\begin{array}{l}\text { Procedures to reduce blood flow to } \\
\text { uterus }\end{array}$ & $34103-12,33833-03,35321-00,33845-00,30385-00,35759-00$ \\
\hline Reclosure of disrupted CS wound* & 30403-03 \\
\hline Repair of bladder or cystostomy & $90480-00,37004-03,37004-02,37011-00,37008-01$ \\
\hline Repair of intestine & $\begin{array}{l}30566-00,30375-19,30565-00,32069-00,30375-24,32003-00,32000-00,32003-01, \\
32000-01,32005-01,32004-01,32006-00,32006-01,32005-00,32004-00,32012-00, \\
32009-00,30375-25,43816-02\end{array}$ \\
\hline Repair ruptured or inverted uterus* & $90478-00,16570-01$ \\
\hline $\begin{array}{l}\text { Transfusion of blood or coagulation } \\
\text { factors }\end{array}$ & $13706-01,13706-02,13706-03,92061-00,92062-00,92206-00$ \\
\hline
\end{tabular}

${ }^{\star}$ Procedure codes in italics were not included in this analysis as these data were not available.

CS, caesarean section; ICD, International Classification of Disease; VPDC, Victorian Perinatal Data Collection.

VPDC were anonymised and all data provided by VPDC on the study participants were de-identified.

\section{RESULTS}

The overall maternal patient population comprised 211060 women, including 1119 women with severe maternal morbidity (cases); the remaining 209941 women were designated as the controls. The prevalence of severe maternal morbidity was 530/100 000 maternities $(0.53 \%)$. The data set included a total of 1002 women who underwent a termination of pregnancy after 20 weeks gestation.

The overall proportion of women in public maternity care $(136665 ; 64.8 \%)$ was higher than in private care $(74395 ; 35.3 \%)$ and there was a higher number of cases than controls in public care $(751 \quad(67.1 \%)$ vs 368 $(64.7 \%)$, respectively; table 2$)$.

There was a higher proportion of women aged $<20$ years in the case group $(3.6 \%)$, but the distribution of cases and controls was otherwise similar across each age group (table 2). The distribution of case and control women across ethnic groups was similar, but there was a higher proportion of cases among Indigenous women compared with non-Indigenous women.

Women were predominantly married (151 245; 71.7\%) and most women were multiparous (119 784; 56.8\%) and had no significant coexisting medical condition reported $(191696 ; 90.8 \%)$. The majority of pregnancies were singleton (207 308; 98.2\%). Nearly three-quarters of women had had an ultrasound prior to 13 weeks gestation (151 362; 71.7\%).

After adjusting for all confounding variables in the data set, compared with the highest IRSD quintile (least deprived) the aOR for the second quintile was 1.23 (95\% CI 1.03 to 1.49$), 0.98$ (95\% CI 0.79 to 1.21$)$ for the third quintile, 1.55 (95\% CI 1.28 to 1.87 ) for the fourth and 1.21 (95\% CI 1.00 to 1.47$)$ for the lowest (most deprived) quintile (table 2). The aOR for women with missing socioeconomic data was 1.74 (95\% CI 1.21 
Table 2 Sociodemographic characteristics of women and associated odds of maternal morbidity

\begin{tabular}{|c|c|c|c|c|}
\hline Variable & $\begin{array}{l}\text { Cases } \\
\mathrm{N}=1119\end{array}$ & $\begin{array}{l}\text { Controls } \\
\mathrm{N}=209941\end{array}$ & Unadjusted OR (95\% Cl) & Adjusted* OR $(95 \% \mathrm{Cl})$ \\
\hline \multicolumn{5}{|c|}{ Socioeconomic category (IRSD quintile) } \\
\hline 1 (least deprived) & $209(18.7)$ & $45167(21.5)$ & 1.0 & 1.0 \\
\hline 2 & $246(22.0)$ & $44242(21.2)$ & $1.20(1.00$ to 1.44$)$ & 1.23 (1.03 to 1.49$)$ \\
\hline 3 & 156 (13.9) & 35948 (17.1) & $0.94(0.76$ to 1.15$)$ & $0.98(0.79$ to 1.21$)$ \\
\hline 4 & $241(21.5)$ & 35522 (16.9) & $1.47(1.22$ to 1.77$)$ & 1.55 (1.28 to 1.87$)$ \\
\hline 5 (most deprived) & $231(20.6)$ & $44371(21.1)$ & $1.13(0.93$ to 1.36$)$ & 1.21 (1.00 to 1.47$)$ \\
\hline Missing & $36(3.2)$ & $4509(2.2)$ & 1.73 (1.21 to 2.46$)$ & 1.74 (1.21 to 2.50$)$ \\
\hline \multicolumn{5}{|c|}{ Patient accommodation class } \\
\hline Private & $368(32.9)$ & 74027 (35.3) & $0.90(0.79$ to 1.02$)$ & $\dagger$ \\
\hline Public & $751(67.1)$ & $135914(64.7)$ & 1.0 & \\
\hline \multicolumn{5}{|l|}{ Age category (years) } \\
\hline$<20$ & $40(3.6)$ & $5782(2.8)$ & $1.29(0.92$ to 1.80$)$ & $1.14(0.81$ to 1.60$)$ \\
\hline $20-24$ & $103(9.2)$ & 23987 (11.4) & $0.80(0.64$ to 1.00$)$ & 0.78 (0.62 to 0.98$)$ \\
\hline $25-29$ & $284(25.4)$ & 52878 (25.2) & 1.0 & 1.0 \\
\hline $30-34$ & 339 (30.3) & 73852 (35.2) & $0.86(0.73$ to 1.00$)$ & 0.87 (0.74 to 1.02$)$ \\
\hline$\geq 35$ & $353(31.6)$ & $53434(25.5)$ & 1.23 (1.05 to 1.44$)$ & $1.22(1.04$ to 1.44$)$ \\
\hline Missing & 0 & 8 & Omitted & \\
\hline \multicolumn{5}{|c|}{ Country of birth (region) } \\
\hline Australia & $860(76.9)$ & $154794(73.7)$ & 1.0 & 1.0 \\
\hline Oceania & $24(2.1)$ & $5792(2.8)$ & 0.75 (0.50 to 1.12$)$ & 0.78 (0.52 to 1.18$)$ \\
\hline UK and Ireland & $29(2.6)$ & $5378(2.6)$ & $0.97(0.67$ to 1.41$)$ & 0.98 (0.67 to 1.42$)$ \\
\hline Europe & $23(2.1)$ & $6064(2.9)$ & $0.68(0.45$ to 1.03$)$ & 0.73 (0.48 to 1.10$)$ \\
\hline Middle East & $11(1.0)$ & $4484(2.1)$ & $0.44(0.24$ to 0.80$)$ & $0.48(0.26$ to 0.87$)$ \\
\hline North America & $6(0.5)$ & $1291(0.6)$ & $0.84(0.37$ to 1.87$)$ & 0.87 (0.39 to 1.94$)$ \\
\hline South America & $3(0.3)$ & $1267(0.6)$ & $0.43(0.14$ to 1.33$)$ & $0.43(0.14$ to 1.35$)$ \\
\hline Africa & $28(2.5)$ & $5292(2.5)$ & $0.95(0.65$ to 1.39$)$ & $1.03(0.71$ to 1.51$)$ \\
\hline Asia & $133(11.9)$ & 24675 (11.8) & $0.97(0.81$ to 1.17$)$ & $1.06(0.88$ to 1.27$)$ \\
\hline Missing & $2(0.2)$ & $904(0.4)$ & $0.40(0.10$ to 1.60$)$ & 0.39 (0.10 to 1.59$)$ \\
\hline \multicolumn{5}{|l|}{ ATSI } \\
\hline Non-ATSI & 1095 (97.9) & 207839 (99.0) & 1.0 & 1.0 \\
\hline ATSI & $23(2.1)$ & $1959(0.9)$ & 2.23 (1.47 to 3.38$)$ & 2.02 (1.32 to 3.09$)$ \\
\hline Missing & $1(0.1)$ & $143(0.1)$ & $1.33(0.19$ to 9.50$)$ & $1.16(0.16$ to 8.44$)$ \\
\hline \multicolumn{5}{|l|}{ Marital status } \\
\hline Married & 795 (71.1) & 150450 (71.7) & 1.0 & $\dagger$ \\
\hline Single & $145(13.0)$ & 27939 (13.3) & $0.98(0.82$ to 1.17$)$ & \\
\hline De facto & $178(15.9)$ & $31081(14.8)$ & $1.08(0.92$ to 1.28$)$ & \\
\hline Missing & $1(0.1)$ & $471(0.2)$ & 0.40 (0.06 to 2.86$)$ & \\
\hline
\end{tabular}

*Variables included in the multivariable model: socioeconomic quintile, maternal age, country of birth, ATSI status, parity, multiple pregnancy, coexisting medical condition, past caesarean section and past spontaneous abortion.

†Not included in multivariable model as either it did not contribute significantly to the fit of the model, or was on the causal pathway (mode of delivery) or considered an outcome (ICU/HDU admission).

ATSI, Aboriginal and Torres Strait Islander; HDU, high dependency unit; ICU, intensive care unit; IRSD, Index of Relative Socioeconomic Disadvantage.

to 2.50). Indigenous status was associated with twice (aOR 2.02; 95\% CI 1.32 to 3.09) the odds of being a case.

There was a U-shaped relationship between age and maternal morbidity with age $<20$ years (aOR 1.14; $95 \%$ CI 0.81 to 1.60 ) and $\geq 35$ years (aOR $1.22 ; 95 \%$ CI 1.04 to 1.44) being associated with increased odds of being a case (although the association with age $<20$ years did not reach statistical significance), compared with the baseline group of 25-29 years (table 2).

Multiple pregnancy was associated with a 2.30 times $(\mathrm{aOR} 2.30 ; 95 \%$ CI 1.71 to 3.10$)$ increased odds of being a case (table 3). Compared with multiparous women, primiparous women were $36 \%$ (aOR 1.36; $95 \%$ CI 1.18 to 1.57 ) more likely to be a case and women with coexisting medical conditions were $39 \%$ (aOR 1.39; $95 \%$ CI 1.16 to 1.65$)$ more likely to be a case. Women who had had one or more previous caesarean sections were almost $80 \%$ (aOR $1.79 ; 95 \%$ CI 1.53 to 2.10 ) more likely to be a case (table 3). Those with 1-2 past spontaneous miscarriages were $25 \%$ more likely (aOR 1.25; 95\% CI 1.08 to 1.44 ) and those with 3 or more past miscarriages were almost $60 \%$ more likely to be a case (aOR $1.57 ; 95 \%$ CI 1.10 to 2.24 ). 
Table 3 Medical and pregnancy-related characteristics of women and associated odds of maternal morbidity

\begin{tabular}{|c|c|c|c|c|}
\hline Variable & $\begin{array}{l}\text { Cases } \\
\mathrm{N}=1119\end{array}$ & $\begin{array}{l}\text { Controls } \\
\mathrm{N}=209941\end{array}$ & $\begin{array}{l}\text { Unadjusted } \\
\text { OR (95\% Cl) }\end{array}$ & $\begin{array}{l}\text { Adjusted } \\
\text { OR }(95 \% \mathrm{Cl})\end{array}$ \\
\hline \multicolumn{5}{|l|}{ Parity } \\
\hline Multiparous & $628(56.1)$ & $119156(56.8)$ & 1.0 & 1.0 \\
\hline Primiparous & $491(43.9)$ & 90785 (43.2) & $1.03(0.91$ to 1.16$)$ & 1.36 (1.18 to 1.57$)$ \\
\hline \multicolumn{5}{|l|}{ Multiple pregnancy } \\
\hline No & $1073(95.9)$ & 206235 (98.2) & 1.0 & 1.0 \\
\hline Yes & $46(4.1)$ & $3706(1.8)$ & 2.39 (1.77 to 3.21$)$ & $2.30(1.71$ to 3.10$)$ \\
\hline \multicolumn{5}{|c|}{ Coexisting medical condition } \\
\hline No & $974(87.0)$ & 190722 (90.9) & 1.0 & 1.0 \\
\hline Yes & $145(13.0)$ & $19219(9.2)$ & $1.48(1.24$ to 1.76$)$ & 1.39 (1.16 to 1.65$)$ \\
\hline \multicolumn{5}{|c|}{ Ultrasound before 13 weeks gestation } \\
\hline Yes & 827 (73.9) & $150535(71.7)$ & 1.0 & $\dagger$ \\
\hline No & $276(24.7)$ & 54977 (26.2) & $0.91(0.80$ to 1.05$)$ & \\
\hline Missing & $16(1.4)$ & $4429(2.1)$ & $0.66(0.40$ to 1.08$)$ & \\
\hline \multicolumn{5}{|l|}{ Past caesarean section } \\
\hline 0 & $862(77.0)$ & $177341(84.5)$ & 1.0 & 1.0 \\
\hline$\geq 1$ & $257(23.0)$ & 32600 (15.5) & 1.62 (1.41 to 1.87$)$ & 1.79 (1.53 to 2.10$)$ \\
\hline \multicolumn{5}{|l|}{ Past ectopic pregnancy } \\
\hline 0 & $1094(97.8)$ & $207007(98.6)$ & 1.0 & $\dagger$ \\
\hline$\geq 1$ & $25(2.2)$ & $2934(1.4)$ & 1.63 (1.09 to 2.42$)$ & \\
\hline \multicolumn{5}{|l|}{ Past spontaneous abortion } \\
\hline 0 & 827 (73.9) & $165832(79.0)$ & 1.0 & 1.0 \\
\hline $1-2$ & $259(23.2)$ & $40301(19.2)$ & $1.29(1.12$ to 1.48$)$ & 1.25 (1.08 to 1.44$)$ \\
\hline$\geq 3$ & $33(3.0)$ & $3808(1.8)$ & $1.74(1.23$ to 2.46$)$ & 1.57 (1.10 to 2.24$)$ \\
\hline \multicolumn{5}{|l|}{ Mode of delivery } \\
\hline $\begin{array}{l}\text { Spontaneous vaginal/ } \\
\text { instrumental vaginal }\end{array}$ & $563(50.3)$ & $145915(69.5)$ & 1.0 & $\dagger$ \\
\hline Planned caesarean & $224(20.0)$ & $34742(16.6)$ & 1.67 (1.43 to 1.95$)$ & \\
\hline Unplanned caesarean & $332(29.7)$ & $29284(14.0)$ & 2.94 (2.56 to 3.37 ) & \\
\hline \multicolumn{5}{|l|}{ ICU/HDU admission } \\
\hline No & $850(76.0)$ & 208718 (99.4) & 1.0 & $\dagger$ \\
\hline Yes & $269(24.0)$ & $1223(0.6)$ & 54. 01 ( 46.57 to 62.64$)$ & \\
\hline
\end{tabular}

*Variables included in the multivariable model: socioeconomic quintile, maternal age, country of birth, ATSI status, parity, multiple pregnancy, coexisting medical condition, past caesarean section and past spontaneous abortion.

†Not included in multivariable model as either it did not contribute significantly to the fit of the model, or was on the causal pathway (mode of delivery) or considered an outcome (ICU/HDU admission).

ATSI, Aboriginal and Torres Strait Islander; HDU, high dependency unit; ICU, intensive care unit.

There was no significant association between maternal country of birth, marital status and public/private maternity care and the odds of severe maternal morbidity (table 2).

\section{DISCUSSION}

\section{Main findings}

This study contributes to the existing body of research exploring risk factors for severe maternal morbidity in Australia. The findings demonstrate that lower socioeconomic position, Indigenous status, older maternal age and a range of clinical factors including multiple pregnancy, primiparity, coexisting medical conditions, a history of previous pregnancy loss and a history of prior caesarean section all increase the odds of severe maternal morbidity.

The recently published Australian national study ${ }^{8}$ which used data from the Australasian Maternity Outcomes Surveillance System (AMOSS) found that women from the lowest socioeconomic group were twice as likely to experience severe complications of pregnancy than women from the highest socioeconomic group. Although there was not a clear dose-response relationship, our findings from this Victorian analysis also show that women from the lowest quintile are more likely than women from the highest socioeconomic quintile to experience severe maternal morbidity. The current study also showed elevated odds of morbidity among women from the fourth quintile.

Research in the UK has suggested that differences between women from higher and lower socioeconomic groups may be attributable to differences in the quality of care women receive, the way they are treated once they present for care, the higher rates of late engagement with antenatal care and emergency caesarean section delivery among women from the lowest socioeconomic group. ${ }^{16}$ This finding requires further exploration in Australia. 
A study conducted in 2010 that investigated ethnic differences in severe maternal morbidity in the UK found a significantly increased risk among non-white women (126/100 000 maternities) compared with white women (80/100 000 maternities).${ }^{17}$ In keeping with the findings of the AMOSS study, the results relating to risk by country of birth are not statistically significant among the Victorian cohort in this analysis. However, the finding that Indigenous women have twice the risk of morbidity suggests that social disadvantage in Australian society is possibly mediated more through Indigenous status than through ethnic group related to country of birth.

This study highlights for the first time the poor maternal health outcomes among Indigenous Australian women (aOR 2.02) in a non-remote setting where barriers to adequate maternity care and access to services are likely to be less compromised than in rural and remote Indigenous communities. Although the number of births to Indigenous women in Victoria is small overall, the rate has almost trebled over the past 30 years ${ }^{11}$ and Victoria therefore provides an appropriate setting in which to explore maternal health outcomes among non-remote Indigenous women. The AMOSS study, which was based on data collected across Australia, found that much of the apparent increase in risk of pregnancy complications experienced by Indigenous women was mitigated after adjustment for socioeconomic position suggesting that socioeconomic factors, rather than Indigenous status per se, are likely to play the major part in the observed inequalities in maternity outcomes between Indigenous and non-Indigenous Australians. In contrast, in the current study, which was based on much larger numbers of women, we observed the persistence of an increased risk of severe morbidity among Indigenous women in Victoria even after adjustment for socioeconomic status (SES). Although data limitations predicated that this analysis was not able to control for smoking and drug and alcohol use, which may be higher among Indigenous women, the results suggest that for Indigenous women in Victoria, being Indigenous itself is a risk factor for maternal morbidity.

In a recent Australian editorial, Michael Marmot emphasised that the 'gap' in life expectancy between Indigenous and non-Indigenous Australians "bespeaks large social inequalities" in Australian society, arising from the circumstances in which "people are born, grow, live, work and age". ${ }^{18}$ If we are to 'close the gap' then further research is needed to explore why such a difference in maternal outcomes persists when service access and availability for Indigenous women in Victoria is ostensibly the same as non-Indigenous women. That poorer outcomes persist among indigenous women is particularly important in Victoria where a dedicated Koori Maternity Service has existed since 2000 with the aim of delivering safe and effective care in a culturally appropriate manner in partnership with the local community and individual woman. ${ }^{19}$
The current perinatal mortality rate for Indigenous babies is 20.4 babies per 1000, compared with 6.6 per 1000 among non-Indigenous babies. ${ }^{19}$ In order to reduce this gap, one of the key tenets of the 'Koolin Balit' statewide plan for Aboriginal health is 'A healthy start to life', focusing on improving antenatal engagement of Aboriginal mothers, reducing smoking and drinking during pregnancy, decreasing the number of low birthweight Aboriginal babies and improving breastfeeding rates. The action plan also emphasises the importance of improving data collection and 'reviewing the existing maternal and child health service model to identify evidence-based approaches to providing support that is more proportionate to the needs of vulnerable families'. This analysis suggests that an inequity in risk of severe maternal morbidity still exists between indigenous and non-indigenous women in Victoria; further research is needed to explore what aspects of services might be modified to address this disparity.

Women 35 years of age and older had a $22 \%$ increased odds of morbidity and young women $<20$ years a $14 \%$ increased odds, although the latter may be a chance finding as illustrated by the CIs. These results are also comparable with the results of the UK analysis ${ }^{9}$ which showed that risk of morbidity increased at both extremes of age (women aged $\geq 35$ years were $90 \%$ more likely to suffer from maternal morbidity and those $<20$ years were $20 \%$ more likely compared with women aged 25-29). The general pregnancy risks associated with older maternal age are well documented. ${ }^{3} 6$ 20-22 The association between the younger extreme of maternal age and maternal morbidity is also not unexpected given the elevated risk of maternal mortality among younger women, ${ }^{23}$ and the known elevated risk of conditions such as hypertensive disorders of pregnancy at younger ages.

Having had a previous caesarean section delivery was associated with moderate and statistically significant increases in risk of severe morbidity. The rise of caesarean section rates in high-income countries, including in Victoria, ${ }^{11}$ has led to extensive research into the risks associated with caesarean delivery, especially in the context of repeated caesareans. For example, previous caesarean section is associated with a significant increase in risk of peripartum hysterectomy and that this risk increases with each subsequent caesarean delivery (OR 2.14 with one previous delivery (95\% CI 1.37 to 3.33), 18.6 with two or more (95\% CI 7.67 to 45.4$)) .{ }^{24}$ These findings have significant implications for counselling of pregnant women about mode of birth.

\section{Strengths and limitations}

One of the major advantages of the existing data infrastructure in Victoria is that information on all births has been routinely collected across the State since 1983 allowing for estimation of the population prevalence of various conditions and procedures and changes in outcomes over time. This also means that the VPDC data 
set is large and that studies using these data are statistically adequately powered.

The birth report also contains relevant demographic information for each woman. However, body mass index and smoking status were not routinely collected prior to 2009 and so, despite being potentially important factors in the analysis of socioeconomic position and maternal outcome, they were not able to be included in this current analysis.

For the purpose of this study, the coding of data into ICD-10 codes allowed for a simple approach to defining morbidity, based on the validated MMOI. ${ }^{10}$ This approach allowed for a clear and inclusive definition of maternal morbidity and which conditions or procedures to include.

At present, the SEIFA coding framework is the only measure of socioeconomic position available nationwide in Australia. ${ }^{25}$ Until 2009, VPDC data were only able to be mapped to postal areas for SEIFA coding which, in Australia, are relatively large, neighbourhood regions. Using an area-based measure of socioeconomic position mapped to a large and varied area potentially blunts the accuracy of the classification and the precision of the results. For example, in Melbourne, many social housing apartment complexes are located within the most affluent suburbs and postcode areas. Arguably, this leads to similar levels of access to healthcare services for all residents in the same area but with significantly different health opportunities for lower socioeconomic groups resulting from lower income, poorer housing, lower levels of education and more adverse health-related behaviours. However, the absence of any individual measures of socioeconomic position in the VPDC data set such as occupation, income and education level meant that this was the only approach that we could take and despite its limitations, which would have led to an attenuation of associations, we were nevertheless able to discern important variations by SES.

\section{CONCLUSION}

In this study, we have shown that socially disadvantaged women in Australia, that is women from disadvantaged areas and those with an Indigenous background, had significantly higher rates of maternal morbidity than women from higher socioeconomic groups and non-Indigenous backgrounds. In keeping with the recently published AMOSS study, ${ }^{8}$ the comparison of findings from the $\mathrm{UK}^{9}$ and the results from Victoria suggest that a similar relationship between socioeconomic position and maternal morbidity exists in both countries, despite universal healthcare. Research in the UK has provided some insight into why these social differences may exist. ${ }^{16}$ In contrast, the reasons for the impact of social disadvantage in Australia remain poorly understood. In addition to highlighting the need for further research into this issue, the current findings from Victoria strongly suggest that social disadvantage needs to be acknowledged as an independent risk factor for adverse maternal outcomes in Australia and incorporated into appropriate policy planning and healthcare programmes.

\section{Author affiliations}

${ }^{1}$ National Perinatal Epidemiology Unit, University of Oxford, Oxford, UK ${ }^{2}$ Department of Obstetrics and Gynaecology, Monash University, Melbourne, Victoria, Australia

${ }^{3}$ The Ritchie Centre, MIMR-PHI Institute of Medical Research, Clayton, Victoria, Australia

${ }^{4}$ Melbourne School of Population and Global Health, The University of Melbourne, Melbourne, Victoria, Australia

Contributors ACL carried out the analysis and wrote the manuscript. ACL, MK and JJK designed the study. MK, JJK, EMW and JO contributed to the writing of the manuscript. All authors read and approved the final manuscript.

Funding This work is supported by funding from the Victorian Government's Operational Infrastructure Support Program. ACL was funded by a scholarship from the Rhodes Trust. MK is funded by a National Institute for Health Research (NIHR) Professorship.

Competing interests $\mathrm{JO}$ and EMW sit on the CCOPMM board which overseas the collection and management of VPDC data.

Ethics approval Monash Health Research Ethics Committee (Project No. 11378B).

Provenance and peer review Not commissioned; externally peer reviewed.

Data sharing statement No additional data are available.

Open Access This is an Open Access article distributed in accordance with the Creative Commons Attribution Non Commercial (CC BY-NC 4.0) license, which permits others to distribute, remix, adapt, build upon this work noncommercially, and license their derivative works on different terms, provided the original work is properly cited and the use is non-commercial. See: http:// creativecommons.org/licenses/by-nc/4.0/

\section{REFERENCES}

1. van Dillen J, Mesman JA, Zwart JJ, et al. Introducing maternal morbidity audit in the Netherlands. BJOG 2010;117:416-21.

2. van Roosmalen J, Zwart J. Severe acute maternal morbidity in high-income countries. Best Pract Res Clin Obstet Gynaecol 2009;23:297-304.

3. Souza JP, Cecatti JG, Parpinelli MA, et al. Maternal morbidity and near miss in the community: findings from the 2006 Brazilian demographic health survey. BJOG 2010;117:1586-92.

4. Wen SW, Huang L, Liston R, et al. Severe maternal morbidity in Canada, 1991-2001. CMAJ 2005;173:759-64.

5. Baskett TF. Epidemiology of obstetric critical care. Best Pract Res Clin Obstet Gynaecol 2008;22:763-74.

6. Waterstone M, Bewley S, Wolfe C. Incidence and predictors of severe obstetric morbidity: case-control study. BMJ 2001;322:1089-93; discussion 93-4

7. Consultative Council on Obstetric \& Paediatric Mortality \& Morbidity. Victorian Perinatal Data Collection, 2014.

8. Lindquist A, Noor N, Sullivan E, et al. The impact of socioeconomic position on severe maternal morbidity outcomes among women in Australia: a national case-control study. BJOG 2014. doi:10.1111/ 1471-0528.13058

9. Lindquist $A$, Knight $M$, Kurinczuk JJ. Variation in severe maternal morbidity according to socioeconomic position: a UK national case-control study. BMJ Open 2013;3:pii: e002742.

10. Roberts CL, Cameron CA, Bell JC, et al. Measuring maternal morbidity in routinely collected health data: development and validation of a maternal morbidity outcome indicator. Med Care 2008;46:786-94.

11. The Consultative Council on Obstetric and Paediatric Mortality and Morbidity. Victoria's mothers and babies: Victoria's maternal, perinatal, child and adolescent mortality. Victoria: Department of Health, State Government of Victoria, 2010/2011.

12. Australian Bureau of Statistics. Chapter 2: What is a SEIFA? Information paper: an introduction to Socio-Economic Indexes for Areas (SEIFA). Canberra: Australian Bureau of Statistics, 2006. 
13. Ros HS, Cnattingius S, Lipworth L. Comparison of risk factors for preeclampsia and gestational hypertension in a population-based cohort study. Am J Epidemiol 1998;147:1062-70.

14. Garner PR, D'Alton ME, Dudley DK, et al. Preeclampsia in diabetic pregnancies. Am J Obstet Gynecol 1990;163:505-8.

15. Duckitt K, Harrington D. Risk factors for pre-eclampsia at antenatal booking: systematic review of controlled studies. BMJ 2005;330:565

16. Lindquist $A$, Kurinczuk J, Redshaw M, et al. Experiences, utilisation and outcomes of maternity care in England among women from different socio-economic groups: findings from the 2010 National Maternity Survey. BJOG 2014. doi:10.1111/1471-0528.13059

17. Knight $M$, Kurinczuk JJ, Spark $P$, et al. Inequalities in maternal health: national cohort study of ethnic variation in severe maternal morbidities. BMJ 2009;338:b542.

18. Marmot M. Social determinants and the health of Indigenous Australians. Med J Aust 2011;194:512-13.

19. Koolin Balit: statewide action plan 2013-2015. Victoria: Victorian Department of Health, 2014.
20. Baskett TF, O'Connell CM. Severe obstetric maternal morbidity: a 15-year population-based study. J Obstet Gynaecol 2005;25:7-9.

21. Philibert M, Deneux-Tharaux C, Bouvier-Colle MH. Can excess maternal mortality among women of foreign nationality be explained by suboptimal obstetric care? BJOG 2008;115:1411-18.

22. Roberts CL, Ford JB, Algert CS, et al. Trends in adverse maternal outcomes during childbirth: a population-based study of severe maternal morbidity. BMC Pregnancy Childbirth 2009;9:1-10.

23. Lewis G. Saving mothers' lives: reviewing maternal deaths to make motherhood safer: 2006-2008. BJOG 2011;118(Supp 1): 1-203.

24. Knight M, Kurinczuk JJ, Spark P, et al. United Kingdom Obstetric Surveillance System Steering Committee. Cesarean delivery and peripartum hysterectomy. Obstet Gynecol 2008;111:97-105.

25. Kennedy B, Firman D. Indigenous SEIFA—revealing the ecological fallacy. Paper presented at population and society: issues, research and policy. 12th Biennial Conference of the Australian Population Association; Canberra, Australia, 2004. 